\title{
Physiology and regulation of biological rhythms in laboratory animals: an overview
}

\author{
F. WOLLNIK*
}

Northwestern University, Department of Neurobiology and Physiology, Evanston, Illinois, USA

\begin{abstract}
Summary
Biological rhythms have been observed in practically all groups of laboratory mammals and at every level of physiological and behavioural organization. Biological rhythms are classified according to their period as ultradian ( $<24 \mathrm{~h})$, circadian $(\sim 24 \mathrm{~h})$, infradian ( $>24 \mathrm{~h})$, and seasonal or circannual rhythms ( $\sim 1$ year). This review outlines what is known about the neurobiology of biological rhythms in mammals and describes the hierarchical order in which ultradian, circadian and infradian rhythms are related to each other. The article does not attempt to catalogue every physiological variable showing rhythmical fluctuations in laboratory mammals. Rather, it focuses on the basic concepts of circadian rhythms and recent advances made in our understanding of the physiology of the internal clock controlling circadian and other biological rhythms.
\end{abstract}

Keywords: Ultradian; Circadian; Infradian; Seasonal, and Circannual Rhythms; Photoperiodism

Many characteristics of laboratory animals vary more or less regularly with specific periods. These temporal variations are called biological rhythms and can be observed not only in the whole organism but also in single organs, tissues or even isolated cells. Biological rhythms cover a wide range of frequencies, from one or several

\footnotetext{
*Present address: Dr Franziska Wollnik, Universität Konstanz, Fakultät für Biologie, Postfach 55 60, D-7750 Konstanz 1, FRG
}

Received 3 March 1988; accepted 8 July 1988 cycles per second (e.g. neuronal activity, heart rate) up to one cycle per year (e.g. seasonal rhythms). Although many biological rhythms are related to external environmental cycles, such as the daily light-dark cycle or seasonal changes in day length and temperature, most of them persist in the laboratory, even under highly standardized conditions. Knowledge of biological rhythms and their consideration in experimental design can help to reduce the variability of quantitative measurements in laboratory animals.

Over the past 30 years research has been focused mainly on biological rhythms that are synchronized to the environmental 24-h cycle, and investigators have tried to determine whether these rhythms reflect only a passive reaction to periodic stimulations from the environment (exogenous rhythms) or whether they are an intrinsic property of the organism (endogenous rhythms). Most of the daily fluctuations in behavioural and physiological variables were found to be truly endogenous since they persist even when no external time cues are present. However, without a synchronizing 'zeitgeber' (time giver) the rhythm will slightly deviate from the 24-h period and eventually 'free-run' with an intrinsic natural period. Halberg (1959) introduced the name 'circadian' rhythms (circa diem, L. = about one day) for these endogenous rhythms, and the remaining spectrum of biological rhythms has hence been divided into 'ultradian' rhythms with periods shorter than $24 \mathrm{~h}$ and 'infradian' rhythms with periods longer than $24 \mathrm{~h}$ (Halberg et al., 1965). Some seasonal rhythms, as well, have been found to persist under constant laboratory conditions. Because their period is approximately 1 year they are classified as 'circannual' rhythms. 


\section{Circadian rhythms}

Circadian rhythms are ubiquitous in animals. They have been documented for practically every laboratory species and at every level of organization within an organism, from physiological to biochemical and behavioural processes. In mammals, birds, and several invertebrates investigators have actually been able to find the location of a circadian clock and have discovered some of the underlying physiological mechanisms that generate circadian rhythms.

\section{Functional properties}

To investigate the mechanisms generating circadian rhythms one could, in principle, study any behavioural or physiological variable. However, some phenomena have more precise rhythms than others and, thus, are more likely to give reproducible results. Commonly investigated circadian rhythms are those of wheel-running activity or overall locomotor activity of small laboratory animals such as hamsters, rats and mice. Spontaneous locomotor activity not only represents the overall physiological status of an animal (Aschoff, 1962) but it is also a convenient feature to study, because it can be continuously measured for many days using automatic recording equipment with little disturbance to the animal.

Figure 1 shows results of some standard experimental procedures used to determine functional properties of circadian rhythms. It is based on an idealized experiment originally presented by Enright (1981). The data are presented in a 'double plot', a format which is commonly used for recordings of locomotor activity but could also be applied to other behavioural or physiological variables. The first part illustrates a free-running circadian rhythm after elimination of all external time cues. In such an experiment, the animal would be kept in a soundproof chamber under conditions of constant illumination or darkness and constant temperature, with food and water available ad libitum. The period of the free-running rhythm ( $\tau$ ) depends on intrinsic factors, such as the physiological status of the individual animal

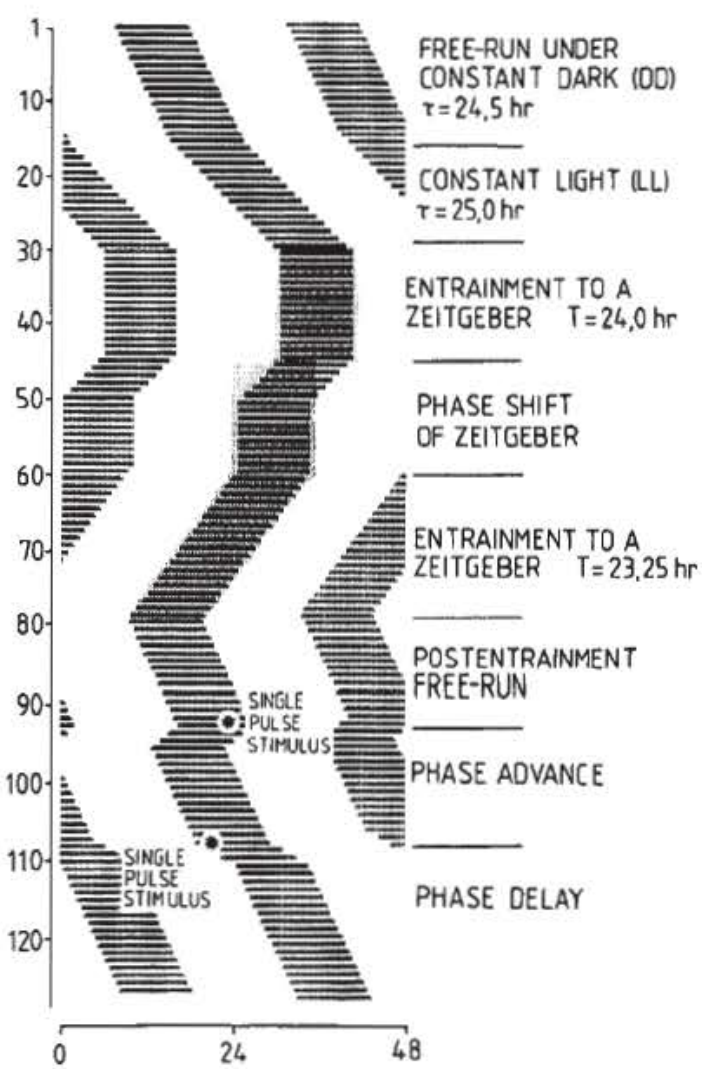

Fig. 1. Idealized data from a hypothetical experiment designed to show period changes of a free-running rhythm caused by internal (age, hormones) or external (light, temperature) stimuli, entrainment by a strong zeitgeber, and phase shifts in response to a single pulse stimulus. The data are presented as a double plot, a format commonly used for the recordings of locomotor activity, where the horizontal axis covers a 48-h period and successive days are plotted from top to bottom. The black horizontal bars represent the physiological variable under investigation, for example wheel-running activity or food intake. A vertical sequence of these bars represents a rhythm with a period of $24 \mathrm{~h}$. A diagonal sequence represents a free-running rhythm with a period longer or shorter than $24 \mathrm{~h}$. The upper portion of the record shows a free-running rhythm with periods of $\tau=24.5 \mathrm{~h}$ and $\tau=25 \mathrm{~h}$. Such a lengthening of the free-running period can be observed, for example, after transferring the animal from continuous dark (DD) to constant light conditions (LL) or after changing the hormonal status of the animal. The middle portion shows entrainment to a zeitgeber with a period of $T=24.0 \mathrm{~h}$ (i.e. a light-dark cycle), entrainment to a phase shift of the zeitgeber, and entrainment to a zeitgeber with a period of $T=23 \cdot 25 \mathrm{~h}$. The lower portion of the record shows the effect of single-pulse stimuli on the circadian rhythm. The first stimulus caused a phase advance, the second a phase delay. The times at which the phase-shifting stimuli were given are indicated by asterisks. (Adapted from Enright, 1981.) 
(e.g. age, hormone levels), and its genetic background (e.g. diurnal or nocturnal species), and on external factors, such as environmental conditions (e.g. light intensity, temperature) and the experimental history of the animal (e.g. breeding conditions, previous experiments) (reviewed in: Aschoff, 1979a,b; Pittendrigh \& Daan, 1976a). Nonetheless, the internal clock is remarkably stable (Pittendrigh \& Calderola, 1973). With the exception of light intensity, these factors have only small effects on the average free-running period. Changes in light intensity have a dramatic effect on the free-running period. Under constant darkness (DD) $\tau$ tends to be longer than $24 \mathrm{~h}$ in many diurnal mammals and shorter than $24 \mathrm{~h}$ in nocturnal species. With an increase in light intensity under constant light (LL) $\tau$ lengthens in both diurnal and nocturnal mammals (Aschoff, 1979a,b).

In the presence of a 24 -h environmental cycle, for example a light-dark (LD) regime, the freerunning rhythm adjusts to this zeitgeber and exhibits a period of exactly $24 \mathrm{~h}$. This adjustment is called 'synchronization' or 'entrainment' and is represented in the second part of Fig. 1. To verify the entrainment one usually demonstrates that the rhythm follows a phase shift, i.e. a single displacement of the zeitgeber along the time axis. The development of a steady-state (i.e. stable) phase relationship between the external zeitgeber and the internal rhythm usually requires several cycles. After termination of entrainment the freerun must always start at a reproducible phase relative to that seen during prior entrainment (Enright, 1981). The strongest zeitgeber for most animals is the light-dark cycle. Other environmental factors that can entrain circadian rhythms are temperature cycles (Aschoff \& Tokura, 1986; Tokura \& Aschoff, 1983), food availability (Boulos \& Terman, 1980), and social cues, which in primates and humans seem to be as important for the entrainment of circadian rhythms as the light-dark cycle (Wever, 1982).

Although entrainment of the free-running rhythm is not restricted to periods of exactly $24 \mathrm{~h}$, the range of periods to which the internal

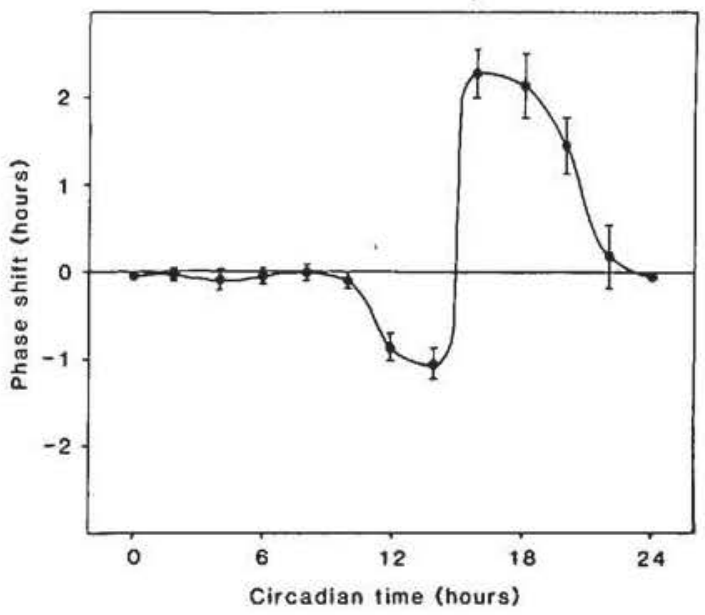

Fig. 2. Phase-response curve (PRC) illustrating the phaseshifting effect of $60-\mathrm{min}$ light pulses on the wheel-running activity rhythm of golden hamsters. The timing of the light pulses is expressed as circadian time (CT) relative to activity onset (=CT 12). Phase advances are plotted as positive phase shifts, phase delays as negative phase shifts. Each point represents the mean phase shift of 6 animals; vertical bars indicate $\pm S D$ (from Takahashi \& Zatz, 1982; (C) Copyright 1982 by the AAAS).

circadian clock can be entrained by a zeitgeber is limited. In mammals this range is relatively narrow (20-28 h; Aschoff \& Pohl, 1978) and depends on the strength (amplitude) of the zeitgeber as well as the strength of the endogenous circadian system of the organism. If the 'range of entrainment' is exceeded, the circadian rhythm will free-run with a period close to that observed under constant conditions. Even then, the signals of the zeitgeber can still modulate the free-running pattern by periodically entraining the rhythm, a phenomenon called 'relative coordination'.

It should be emphasized that measurements of circadian rhythms such as locomotor activity or hormonal profiles do not directly represent the state of the internal pacemaker system, since the pacemaker signal can be subject to many internal and external modifications. The genuine status of the pacemaker system is described only by the period length under free-running conditions and the steady-state phase under entrainment 
(Pittendrigh, 1981). In Fig. 1, the last part of the data represents a common experiment used to examine the effects of light or other stimuli, such as hormones, neurotransmitters, and drugs, on the circadian clock. If an animal that has been kept in constant darkness is exposed to a light pulse of 1-60 min, the timing of the activity onset will be permanently modified, so that its freerunning rhythm will show a 'phase-shift'. Depending on the time of day at which it is applied the light pulse may induce an advance or a delay of the activity onset or have no effect at all. The time of the light pulse is usually given in 'circadian time' relative to the activity onset. In nocturnal species the activity onset is defined as circadian time 12 (CT 12); the animal is active during its 'subjective night' (CT 12-24) and is inactive during its 'subjective day' (CT 0-12). The magnitude and direction of the phase shift is plotted in a 'phase response curve' (PRC) as a function of the circadian time at which the stimulus was given. PRCs to light pulses have the same general shape as shown in Fig. 2 for both nocturnal and diurnal animals (reviewed in Daan \& Pittendrigh, 1976). If the light pulse is given during the late subjective night (CT 18-24) the rhythm will be advanced; if it is given during the early subjective night (CT 12-15) the rhythm will be delayed. If the light pulse is given during the subjective day (CT 0-12), little or no phase shifts occur. The PRC also predicts the repeated daily adjustments necessary to synchronize the endogenous free-running period $(\tau)$ to the period $(T)$ of the external light-dark cycle. Consequently, a phase delaying light pulse causes a temporary lengthening of the period, and a phase advancing light pulse causes a temporary shortening of the period. Under conditions of entrainment the daily phase shift $\Delta \emptyset$ is equal to the difference between the entraining period $T$ and the freerunning period $\tau: \Delta \emptyset=T-\tau$ (Daan \& Pittendrigh, 1976; Pittendrigh, 1981). The PRC approach has been used in mammals to describe how light or administration of various drugs and neurotransmitters can alter the phase and period of the circadian clock (Turek, 1985, 1987; Zatz, 1979; Zatz \& Brownstein, 1979, 1981; Zatz \&
Herkenham, 1981) thus providing clues as to which neural mechanisms might be involved in the generation and entrainment of circadian rhythms.

\section{Neuronal organization of biological rhythms in mammals}

The location of the circadian clock in mammals was first discovered by Richter (1967). After removing various endocrine glands and lesioning specific parts of the rat brain he concluded that a circadian clock must be located near the 'ventral median nucleus' of the hypothalamus. Further studies in the 1970 s determined the primary location more specifically in the suprachiasmatic nuclei (SCN) of the hypothalamus (Moore \& Eichler, 1972; Stephan \& Zucker, 1972a).

The SCN are bilaterally symmetrical nuclei located near the third ventricle and directly above the optic chiasm (Fig. 3a). The SCN of rodents have an oval shape, those of cats and monkeys are more irregularly shaped (Lydic et al., 1982). In rats, each nucleus is about $300 \mu \mathrm{m}$ in transverse diameter and $600 \mu \mathrm{m}$ in length and contains about 8000 neurons organized in recognizable subpopulations (Van den Pol, 1980). So far, two specific substances, the peptides vasopressin and vasoactive intestinal polypeptide (VIP), have been identified as being produced by SCN neurons, although they are only found in less than half of all neurons (Sofroniew \& Weindl, 1982). Other neuropeptides and neurotransmitters, such as somatostatin, serotonin, corticotropin-releasing factor, avian pancreatic polypeptide, neuropeptide $\mathrm{Y}$, and gamma-aminobutryc acid (GABA) have been found in afferent nerve fibres to the SCN (Card \& Moore, 1982; Groos, 1982; Sofroniew \& Weindl, 1982; Van den Pol \& Tsujimoto, 1985).

The primary input into the $\mathrm{SCN}$ is the retinohypothalamic tract (RHT) through which the entraining signals of the external light-dark cycle reach the internal clock (Hendrickson et al., 1972; Moore \& Lenn, 1972). The RHT is common to all mammals studied so far. It leaves 

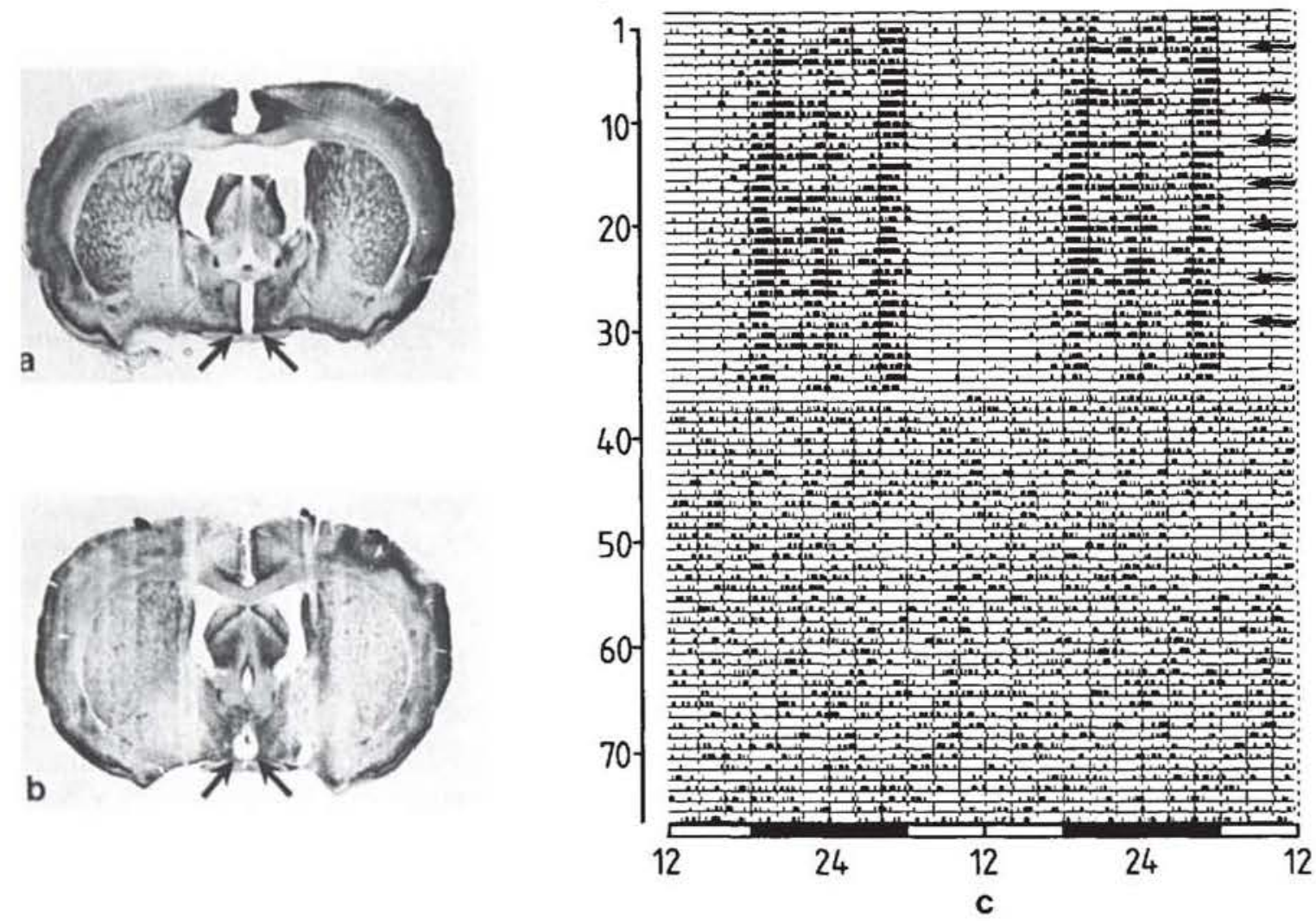

Fig. 3. Effect of a complete SCN lesion on the wheel-running activity pattern of a laboratory rat. (a) Coronal section through the intact midbrain $(60 \mu \mathrm{m}$ thick, thionin staining). The arrows indicate the bilateral SCN. (b) Coronal section as in (a) after complete SCN lesion. The arrows indicate the site of the lesion. (c) Double plotted wheel-running activity record of a female $\mathrm{LEW} / \mathrm{Ztm}$ rat maintained under a light-dark cycle of $12 \mathrm{~h}$ light and $12 \mathrm{~h}$ dark. Day time hours and the light-dark schedule are indicated below the record. Numbers to the left denote the day of the experiment. Each raster mark in the record represents a certain number of wheel revolutions over $15 \mathrm{~min}$. The upper portion illustrates the wheel-running activity pattern normally seen in LEW/Ztm females. The days of oestrus are indicated by small arrows on the right hand side of the record; the oestrous cycle was monitored by vaginal smears. Note the oestrous correlated changes in the onset, level and pattern of the wheelrunning activity. Rhythmicity disappeared completely after the SCN was lesioned on day 36 of the experiment.

the optic nerve at the optic chiasm and terminates in the SCN (Moore, 1978). In mammals, both blinding and bilateral transection of the optic nerve between retina and optic chiasm totally eliminate entrainment of circadian rhythms to light, while transection of the optic tract beyond the optic chiasm does not disturb entrainment in an obvious manner (Stephan \& Zucker, 1972b; Moore \& Klein, 1974; Moore, 1978). However, more detailed physiological and anatomical studies have revealed that some information can reach the SCN through other pathways (Groos,
1982; Rusak, 1982; Sofroniew \& Weindl, 1982; Moore \& Card, 1985). In addition to the direct visual input through the RHT, the $\mathrm{SCN}$ receive indirect visual input via the ventral lateral geniculate nuclei (Swanson et al., 1974; Card \& Moore, 1982; Harrington et al., 1987; Pickard, Ralph \& Menaker, 1987), which are part of the central visual system. Another indirect visual input might reach the $\mathrm{SCN}$ through serotonergic fibres from the raphe nuclei (Ajika \& Ochi, 1978) which themselves receive a retinal input (Foote et al., 1978). Neural inputs from the septum, 
hypothalamus, thalamus, hippocampus and midbrain as well as commissural connections between the bilateral SCN have also been demonstrated (Pickard, 1982). Efferent projections of the SCN terminate in other hypothalamic nuclei (paraventricular nucleus, dorsomedial hypothalamic nucleus), in the thalamus (paraventricular thalamic nucleus) and in the midbrain (Swanson \& Cowan, 1975; Berk \& Finkelstein, 1981; Stephan et al., 1981; Sofroniew \& Weindl, 1982).

The following experiments indicate that the SCN play an important role in the normal expression of circadian rhythms:

(1) SCN lesions: A variety of behavioural and physiological circadian rhythms, including locomotor activity, feeding, drinking, body temperature, synthesis and/or secretion of several hormones, and the sleep-wake cycle, can be severely disrupted or completely abolished by complete bilateral SCN lesions or isolation of the $\mathrm{SCN}$ from other neural structures (reviewed in: Moore, 1978, 1983; Rosenwasser \& Adler, 1986; Rusak \& Zucker, 1979; Turek, 1985). An example is given in Fig. 3c which illustrates the effect of complete $\mathrm{SCN}$ lesions on the wheelrunning activity pattern of laboratory rats. Follow-up studies on rats whose SCN had been lesioned immediately after birth have shown that the function of the SCN were not taken over by other parts of the brain (Mosko \& Moore, 1978). SCN lesions also disrupt oestrous cyclicity and photoperiodic time measurement, two components of the reproductive process that depend upon the circadian system for temporal information (Rusak \& Morin, 1965; Stetson \& WatsonWhitmyre, 1976; Turek et al., 1980).

(2) Demonstration of intrinsic oscillations: Circadian rhythms in multi-unit neuronal activity have been recorded in the SCN and several other regions of the rat brain. After surgical isolation of the $\mathrm{SCN}$ within a 'hypothalamic island', circadian firing patterns persist in the $\mathrm{SCN}$ but can no longer be recorded in other parts of the brain (Inouye \& Kawamura,
1979). This indicates that circadian rhythms in neuronal activity originate in the SCN. The neural circadian rhythms in the $\mathrm{SCN}$ showed characteristic properties (e.g. a free-running period) expected of an endogenous circadian oscillator (Inouye \& Kawamura, 1982; Inouye, 1984). The $\mathrm{SCN}$ seem to maintain a neural or hormonal circadian rhythm even in vitro (Green \& Gillette, 1982; Shibata et al., 1984; Earnest \& Sladek, 1987). Using 2-deoxyglucose autoradiography, researchers have also found that in a wide range of species glucose consumption follows a circadian rhythm in the SCN (Flood \& Gibbs, 1982; Schwartz, Reppert, Eagan \& MooreEde, 1983). SCN metabolic activity is high during the subjective day and low during the subjective night in both nocturnal and diurnal animals (Schwartz et al., 1983). In rats the circadian rhythm of glucose uptake in the SCN can be detected as early as several days before birth, prior to the arrival of any retinal projections (Reppert \& Schwartz, 1983, 1984).

(3) Electrical and chemical stimulations: In hamsters and rats, short electrical stimulation of the $\mathrm{SCN}$ has a similar phase-shifting effect on the circadian rhythm as light (Rusak \& Groos, 1982). Timed injections of pharmacological agonists or antagonists of neurotransmitters found in SCN cells and axons have been shown to mimic or block the phase-shifting effect of light (reviewed in: Turek, 1985, 1987; Rosenwasser \& Adler, 1986). For example, photic stimulation increases the concentration of acetylcholine in the SCN (Murakami et al. 1984).

Intracerebroventricular injections of carbachol, an acetylcholine agonist, mimic the phase shifting effect of light (Zatz \& Herkenham, 1981; Earnest \& Turek, 1983), whereas mecamylamine, a cholinergic antagonist, blocks the phase-shifting effect of light (Keefe et al., 1987). This suggests that acetylcholine may be involved in the transmission of light-dark information to and within the circadian clock. 
(4) SCN-Transplantation: Only recently has the pacemaker function of the $\mathrm{SCN}$ been demonstrated in the most direct way. By transplanting fetal neural tissue containing the anlagen for the SCN into arrhythmic SCNlesioned hamsters and rats circadian rhythmicity of locomotor activity has been restored (Kawamura \& Nithonmatsu, 1985; Aguilar-Roblero et al., 1986; Lehman et al., 1987). It remains to be shown whether pacemaker properties such as phase and period of the donor can also be transferred. This would demonstrate that the transplanted tissue actually generates the restored rhythm rather than simply having a permissive effect. The specificity of transplanting $\mathrm{SCN}$ tissue has been questioned lately after it was observed that circadian rhythms could also be restored by transplanting fetal cortical tissue into the lesion site (GarciaHernández et al., 1987).

The circadian system of mammals is thought to consist of multiple circadian oscillators which are coupled to each other in both a hierarchical and non-hierarchical (mutual) manner (reviewed in: Pittendrigh, 1960, 1974; Rusak, 1979; Rosenwasser \& Adler, 1986). While these oscillators normally are synchronized in order to generate a single pacemaker signal, certain conditions can cause their desynchronization.

The most prominent example of desynchronization is 'splitting', the dissociation of the circadian rhythm into two or sometimes even more distinct components (reviewed in: Pittendrigh, 1974; Pittendrigh \& Daan, 1976b; Turek et al., 1982; Rosenwasser \& Adler, 1986). A characteristic feature of splitting is the temporary free-run of the two components with different periods. The two components often resynchronize after reaching a $180^{\circ}$ phase-relation and subsequently free-run with identical periods. Splitting has been reported for a number of mammalian species, including hamsters (Earnest \& Turek, 1982; Turek et al., 1982), rats (Boulos \& Terman, 1979; Cheung \& McCormack, 1983), tree shrews (Hoffman, 1971) and monkeys (Fuller et al., 1979). In hamsters it has been evoked by exposing the animals to long-term bright light conditions or SCN lesions (Rusak, 1977; Earnest \& Turek, 1982). In other species splitting has also been observed after long-term exposure to constant dark (Hoffman, 1971), administration of pharmacological substances (Wirz-Justice, Groos \& Wehr, 1982), and manipulations of the endocrine system by gonadectomy and hormone replacement (Morin, 1980; Morin \& Cummings, 1982). In hamsters, splitting disappears rapidly, when the animals are transferred into constant darkness (Earnest \& Turek, 1982). The splitting phenomenon has led to the assumption that at least two mutually coupled oscillators underlie the circadian locomotor activity rhythm (Pittendrigh \& Daan, 1976b). Because of the splitting phenomenon and the fact that even the undisturbed, non-split activity rhythms of many mammalian species display quite complex patterns made up of two or more activity components (Aschoff, 1962), it is widely accepted today that the circadian clock of mammals is a multioscillatory system.

Although multiple circadian oscillators are assumed to lie in the $\mathrm{SCN}$, there is also evidence for the presence of oscillators outside the SCN. For example, not all circadian rhythms disappear after complete SCN lesions. In hamsters, both circadian and ultradian rhythms in wheelrunning activity have been reported to persist in individual animals (Rusak, 1977). In rats, periodic feeding can entrain food-anticipatory rhythms in a number of physiological parameters (reviewed in: Boulos \& Terman, 1980; Aschoff et al., 1983), and those rhythms persist after $\mathrm{SCN}$ lesions showing the same characteristics as before (Krieger et al., 1977; Stephan et al., 1979a,b; Stephan, 1982, 1984). These results indicate that the food entrainable pacemaker is functionally and anatomically independent from the 'classical', i.e. light entrainable, circadian system within the SCN (Gibbs, 1979; Boulos et al., 1980). The search for the food entrainable pacemaker has focused on the ventromedial nucleus of the hypothalamus because destruction of this nucleus can abolish the food-anticipatory rhythms (Krieger, 1980; Inouye, 1982). Recently, 
the circadian locomotor activity rhythm of completely arrhythmic SCN lesioned rats could be restored by chronic administration of methamphetamine in the drinking water (Honma et al., 1987). Since the rhythm was obviously not generated by the SCN nor entrained by the lightdark cycle, one must assume that the methamphetamine activated an endogenous oscillatory mechanism outside the SCN that is probably identical with the food-anticipatory pacemaker system.

\section{Genetic determination}

A number of characteristic properties of circadian rhythms have been shown to be genetically determined. To investigate the genetic background of circadian rhythms in mammals quantitative genetic methods of variance and covariance analysis (Hegmann \& Possidente, 1981) have been applied to inbred strains of small laboratory animals like mice, hamsters and rats (Table 1). In mice, there are significant differences between strains in the free-running period of wheel-running activity (Ebihara et al., 1978) and food and water intake (Possidente \&

Table 1. Inbred strains of laboratory mammals used for genetic analyses of biological rhythms

\begin{tabular}{|c|c|c|}
\hline \multirow[t]{13}{*}{ Mice } & BALB/CBYJ & Possidente \& Hegmann (1980) \\
\hline & BALB/cIbg & Connolly \& Lynch (1981) \\
\hline & $\mathrm{C} 3 \mathrm{H} / \mathrm{HeJ}$ & Possidente \& Hegmann (1980) \\
\hline & $\mathrm{C} 3 \mathrm{H} / 2 \mathrm{lbg}$ & Connolly \& Lynch (1981, 1983) \\
\hline & $\mathrm{C} 57 \mathrm{BL} / 6 \mathrm{~J}$ & Connolly \& Lynch $(1981,1983)$ \\
\hline & & Ebihara et al. (1978) \\
\hline & C57BL/10Sn & Ebihara et al. (1978) \\
\hline & & Possidente \& Hegmann (1980) \\
\hline & $\mathrm{C} 58 / \mathrm{J}$ & Possidente \& Hegmann (1980) \\
\hline & DBA/IBG & Connolly \& Lynch (1981) \\
\hline & $\mathrm{DBA} / 1 \mathrm{~J}$ & Possidente \& Hegmann (1980) \\
\hline & DDK & Ebihara et al. (1978) \\
\hline & MOL-A & Ebihara et al. (1978) \\
\hline \multirow[t]{5}{*}{ Rats } & $\mathrm{ACl} / \mathrm{Ztm}$ & Büttner \& Wollnik (1984) \\
\hline & $\mathrm{LEW} / \mathrm{Ztm}$ & Wollnik et al. (1987) \\
\hline & $\mathrm{AS} / \mathrm{Ztm}$ & \\
\hline & $\mathrm{BH} / \mathrm{Ztm}$ & Büttner \& Wollnik (1984) \\
\hline & $\mathrm{BS} / \mathrm{Ztm}$ & \\
\hline \multirow{5}{*}{$\begin{array}{l}\text { Golden } \\
\text { hamsters }\end{array}$} & CB & \multirow{5}{*}{ Hotz \& Turek (1987) } \\
\hline & LHC & \\
\hline & LSH & \\
\hline & MHA & \\
\hline & PD4 & \\
\hline
\end{tabular}

Hegmann, 1980) as well as in the circadian phase and period of body temperature (Connolly \& Lynch, 1981, 1983). Furthermore, a positive genetic correlation was found between the phase and the period of the circadian rhythms of food intake and water consumption, which suggests that both parameters are regulated by a common physiological mechanism and would respond to natural selection as a single circadian complex under common gene control (Possidente \& Hegmann, 1980). In hamsters, strain differences have been demonstrated for the free-running period, the circadian phase of activity onset and splitting (Hotz \& Turek, 1987). Recently, a spontaneous hamster mutant has been isolated that has a remarkably short free-running period of only $20 \mathrm{~h}$ (Ralph \& Menaker, 1987). In rats, strain differences have been demonstrated for the free-running period and the daily pattern of spontaneous locomotor activity (Büttner \& Wollnik, 1984). Two inbred strains of rats, $\mathrm{BH} / \mathrm{Ztm}$ and $\mathrm{LEW} / \mathrm{Ztm}$, showed an unusual bimodal and trimodal, respectively, activity pattern. A classical genetic analysis revealed that the trimodal activity pattern of the LEW/Ztm strain has a recessive single-gene mode of inheritance (Wollnik et al., 1987).

Another approach to investigate the genetic background of circadian rhythms is to study strains with known mutations in the visual or central nervous system. Mutations which in early development modify retinal pigment and visual pathways also modify developmental and functional properties of circadian rhythms. For example, the free-running circadian period of both albino and pinkeye-dilute mice is shorter than that of pigmented mice (Possidente et al., 1982). Mice of an anophthalmic strain (ZRDCTAn) with varying degrees of hypogenesis of the mediobasal hypothalamus and SCN that showed a partially or completely arrhythmic wheelrunning activity pattern had less than one third of the typical number of cells in the SCN (Scheuch et al., 1982). A strain of laboratory rats with a genetic inability to produce vasopressin (Long Evans, Brattleboro strain) showed no obvious alterations or deficits in their circadian 
rhymicity (Peterson et al., 1980) indicating that the circadian clock does not involve the vasopressin neurons of the SCN. Inbred strains of laboratory animals with genetically fixed modifications of the circadian system would provide a good test case for SCN transplantation experiments, since the transfer of characteristic properties of a clock mutant could easily be verified.

\section{Ultradian rhythms}

Ultradian rhythms are defined as biological rhythms with a period significantly shorter than $24 \mathrm{~h}$, ranging from 1 to $12 \mathrm{~h}$ (Halberg et al., 1965). Typical examples of ultradian rhythms are the repetition of rapid eye movements (REM) every $90 \mathrm{~min}$ during sleep in humans and some mammalian species and ultradian rhythms in physiological parameters associated with REM sleep (reviewed in Schulz \& Lavie, 1985). Other examples are episodic secretion patterns of various hormones, such as luteinizing hormone (peaks every $0 \cdot 5-3 \mathrm{~h}$ ), growth hormone (peaks every $3 \mathrm{~h}$ ), and corticosterone (reviewed in Van Cauter \& Honinckx, 1985), and short-term behavioural rhythms in locomotor activity or food intake of small mammals (Gerkema \& Daan, 1985; Honma \& Honma, 1985a). Ultradian rhythms are more difficult to investigate than circadian rhythms for the following reasons. First, ultradian rhythms include a wide range of rhythmic phenomena which do not necessarily share common properties. For example, some ultradian rhythms are true periodic processes with a consistent period, whereas others are rather episodic with variable time lags between single events (Aschoff \& Gerkema, 1985). Second, unlike circadian rhythms, which have evolved in adaptation to the 24 -h fluctuations of the environment, ultradian rhythms do not correspond to any known physical cycle in the environment, and a general functional significant like that of circadian rhythms has not been demonstrated yet (Gerkema \& Daan, 1985). Third, in order to detect ultradian rhythms in raw data and to discriminate truly rhythmic phenomena from random stochastic processes it is often necessary to use elaborate recording and analysing techniques, such as periodogram and power spectrum analyses (Van Cauter, 1981; Wollnik \& Döhler, 1986).

Since many ultradian rhythms are related to metabolic processes (e.g. food intake, hormone secretion, urinary excretion) and sometimes even show an allometric correlation between period and body weight (Daan \& Slopsema, 1978; Gerkema \& Daan, 1985), several authors have suggested that digestive functions are involved in the generation of ultradian rhythms (reviewed in: Aschoff, 1962; Daan \& Aschoff, 1981). However, it is now well established that their most likely site of generation is the nervous system (reviewed in Schulz \& Lavie, 1985). Two general models for the generation of ultradian rhythms have been proposed. The first assumes the existence of an ultradian pacemaker system that is anatomically and functionally independent from the circadian system. It was developed by Kleitman $(1961,1982)$ and is based on data on the 90-min sleep-wake cycle in humans. This independent ultradian pacemaker system can either be a periodic oscillatory system or a homeostatic renewal process (Gerkema \& Daan, 1985). The second model views ultradian rhythms as a result of desynchronization of several circadian oscillators that are coupled to each other in different phase relations (Pittendrigh, 1974). Considering the broad variety of ultradian rhythms it is not surprising that results have been reported in support of both models.

For example, an independent ultradian oscillator appears to generate the feeding and locomotor activity rhythms in the common vole (Daan \& Slopsema, 1978; Daan \& Aschoff, 1981). In this species a total lesion of the SCN completely abolished the circadian rhythm but did not affect the ultradian rhythmicity (Gerkema \& Daan, 1985). Similarly, complete SCN lesions in rats did not disrupt the pulsatile pattern of $\mathrm{LH}$ release (Soper \& Weick, 1980) suggesting that ultradian and circadian rhythms in hormone release are generated by different neural centres. In both cases, investigators identified the arcuate nucleus (ARC) of the hypothalamus as a possible 
candidate for the ultradian pacemaker system (Gerkema \& Daan, 1985; Knobil \& Hotchkiss, 1985). The same neuronal site has also been suggested as the location of a pacemaker for ultradian rhythms in growth hormone release in rats (Eikelboom \& Tannenbaum, 1983). However, even if ultradian rhythms are generated by an independent ultradian pacemaker they can still be modulated by the circadian system. Such a modifying influence of the circadian system has been found in the pulsatile patterns of hormone release (reviewed in Turek \& Van Cauter, 1988) and the behavioural ultradian rhythms of voles (Gerkema \& Daan, 1985).

Behavioural activity patterns of small laboratory mammals that show short-term fluctuations are also often referred to as ultradian rhythms (reviewed in: Aschoff, 1962; Daan \& Aschoff, 1981). In laboratory rats, behavioural ultradian rhythms appear prior to circadian rhythms during early developmental stages (Honma \& Honma, 1985b). They are also prominent during aging (Albers et al., 1981a) and under long-term exposure to constant light (Albers et al., 1981a; Honma \& Honma, 1985a) when the circadian rhythmicity fades or disappears. These findings have even led to the suggestion that ultradian rhythms may be the underlying time pattern from which circadian rhythms are then derived by frequency and amplitude modulation (Honma \& Honma, 1985a,b).

The following observations on behavioural ultradian rhythms in laboratory rats, however, do not support the existence of an independent ultradian pacemaker. First, ultradian activity rhythms in adult laboratory rats have so far been described only for particular animals (Stephan, 1983) or specific inbred strains, e.g. LEW/Ztm (Büttner \& Wollnik, 1984), and may thus not be characteristic for the normal temporal organization of rat behaviour. Second, since complete $\mathrm{SCN}$ lesions in the inbred strain LEW/Ztm abolished both ultradian and circadian rhythms of wheel-running activity, the SCN is apparently involved in the control of both rhythms (Wollnik \& Turek, 1987). Third, the expression of ultradian rhythms in the adult LEW/Ztm rats depends on the hormonal status of the animals; high serum levels of oestrogen suppress ultradian rhythms in both male and female rats (Wollnik \& Döhler, 1986). Since similar effects of hormones on the coupling between circadian oscillators have been demonstrated for hamsters (Morin, 1980) and mice (Daan et al., 1975), ultradian rhythms in locomotor activity may be the result of the combination of several circadian oscillators coupled to each other in various phase relations.

The diversity of ultradian rhythms is also apparent in the domain of their functional relevance. For example, the normal reproductive function of humans and primates depends on a specific ultradian timing of the release of gonadotropin-releasing hormone by the hypothalamus and luteinizing hormone by the pituitary (Knobil \& Hotchkiss, 1985). In voles, the ultradian feeding and activity rhythms are essential for providing optimal timing of food intake and digestive pauses as well as interindividual social synchrony among conspecifics in order to reduce the predator risk for the individual animal (Daan \& Slopsema, 1978; Daan \& Aschoff, 1981).

Ultradian rhythms often have periods of 3, 4, 4.8 , or $6 \mathrm{~h}$. Since these periods are subharmonics of the circadian period, one must verify that they are clearly detectable in the raw data and not mere artifacts of the statistical method used for data analysis. The predominance of integer ratios of the circadian period can be interpreted both as a result of the desynchronization of a multi-oscillatory circadian pacemaker system and as a sign for independent ultradian oscillators that have evolved during the evolutionary process because they could maintain a constant phase relationship with the circadian rhythm (Broughton, 1985). Organisms with ultradian rhythms of $3,4,4 \cdot 8$ or $6 \mathrm{~h}$ periods should have significant advantages over organisms with ultradian rhythms of, for example, $1 \cdot 7,5$ or $7 \mathrm{~h}$ periods, since the latter would never stay in phase with each other and the major environmental periodicities. 
Although there is no doubt today that many behavioural and physiological events follow an ultradian temporal pattern, no other class of biological rhythms is characterized by such a diversity of rhythmic phenomena, generating mechanisms, and biological functions. Therefore, caution is warranted when results from observations of one ultradian phenomenon are being generalized to other ultradian rhythms.

\section{Infradian rhythms}

Infradian rhythms are defined as biological rhythms with a period significantly longer than 1 day, but less than 1 year (Halbert et al., 1965). In mammals, many infradian rhythms are related to functional changes in the ovary and can therefore be observed only in females of spontaneous ovulatory species. Oestrous is induced by changes in the levels of the pituitary hormones luteinizing hormone ( $\mathrm{LH}$ ) and follicle-stimulating hormone (FSH) (reviewed in Mahesh, 1985) and occurs at regular intervals characteristic for each species (mice, rats, hamsters: once every 4-5 days, guineapigs, sheep, goats: once every 13-20 days). The resulting physiological changes in the ovaries include fluctuations of oestrogen and progesterone secretion which in turn influence behavioural parameters such as spontaneous locomotor activity, food intake, aggression and sexual behaviour (reviewed in Campbell \& Turek, 1981).

The period of behavioural heat on or around the day of ovulation is characterized by an increased level of activity (rats: Albers et al., 1981b, mice: Guttman et al., 1975, hamsters: Finkelstein et al., 1978). In hamsters and rats, activity starts earlier on the day of oestrous resulting in a 'scalloping' of the activity onset in intervals of 4 or 5 days (Albers et al., 1981b; Morin et al., 1977; Sridaran \& McCormack, 1977). Furthermore, the activity pattern undergoes complex changes during the oestrous cycle (Takahashi \& Menaker, 1980). Figure 3c shows an example of oestrous-correlated modulation of wheel-running activity in a laboratory rat. On the day of ovulation activity starts earlier and retains a constant high level throughout the activity phase. On the days following ovulation, activity starts later and shows a bi- or trimodal pattern. By looking at continuous recordings of locomotor activity one can easily predict the day of ovulation. Changes in the onset, intensity and pattern of wheel-running activity are almost as reliable a marker of the oestrous cycle as vaginal smears (Sridaran \& McCormack, 1977).

The oestrous cycle is an endogenous rhythm that depends on various components of the neuroendocrine system located in the ventromedial arcuate region and the preoptic suprachiasmatic area of the hypothalamus (reviewed in Mahesh, 1985). A striking feature of the oestrous cycle is the circadian timing of many oestrous related events. For example, ovulation and the LH surge on the day of proestrus maintain a constant phase relation with the external light-dark cycle and follow a phase shift of this zeitgeber (Alleva et al., 1968; Stetson \& Gibson, 1977; Gallo, 1981). Even in the absence of external time cues, the oestrous cycle is closely associated with the circadian system. For example, the oestrous cycle of hamsters and rats free-runs with a period 4 or (in some rats) 5 times that of the circadian activity rhythm (Fitzgerald \& Zucker, 1976; Albers et al., 1981b). Female hamsters whose activity rhythm was split after exposure to constant light show two LH surges, each occurring $0-4 \mathrm{~h}$ before the onset of one activity component (Swann \& Turek, 1985).

The circadian timing of the oestrous cycle seems to be controlled by the SCN. Bilateral lesions of the SCN not only abolish the preovulatory LH surge and thus impede ovulation but also cause a state of persistent oestrous in hamsters and rats (Stetson \& Watson-Whitmyre, 1976). Since the preovulatory LH surge is normally triggered by an increased secretion of gonadotropin releasing hormone ( $\mathrm{GnRH}$ ) from the mediobasal hypothalamus (Levine \& Ramirez, 1982) the SCN must somehow be coupled to those GnRH neurons. However, it is not clear yet which pathways and neurotransmitters are involved in the transmission of the circadian timing signal to the mediobasal hypothalamus (reviewed in: Turek \& Van Cauter, 1988). 
Except those infradian rhythms associated with the oestrous cycle only few others have been reported. For example, in dormice kept under various laboratory conditions infradian rhythms with a period of about 2 months have been demonstrated for several physiological functions, such as body weight, food and water intake, and weight of liver, testis, and adrenal and salvary gland (Mrosovsky et al., 1980). Another example is the weekly, or circaseptadian, rhythm of enzyme activity in the rat pineal (Vollrath, 1982). Since this weekly rhythm was only found in animals that had been kept under normal laboratory conditions and had not been demonstrated to free-run with a period of about 7 days, it is likely that it is an example of an exogenous rhythm induced by periodic events in the laboratory environment, such as work schedules of animal care personnel, heater operation, street noise, etc.

\section{Seasonal and circannual rhythms}

Many biological activities and reproductive functions are restricted by environmental conditions such as temperature, day length, or food availability to a time of the year when they are most likely to be successful. In addition, many behavioural, physiological and morphological processes undergo annual fluctuations that are directly or indirectly related to seasonal variations in the environment (reviewed in Gwinner, 1981). These seasonal rhythms may be referred to as 'circannual' rhythms only if it is has been demonstrated that they persist with a period of about 1 year for at least two cycles under constant environmental conditions. Annual rhythms of body weight or reproductive functions that can be observed in many mammals under natural conditions have been confirmed as a circannual rhythm only in a few species, such as ground squirrels (Pengelly \& Asmundson, 1974).

In many seasonal breeding animals, seasonal changes in reproductive functions are not observed under constant laboratory conditions. Their reproductive state is a direct result of the day length, or 'photoperiod', and thus can be manipulated using different light-dark cycles (reviewed in: Hoffmann, 1981; Keefe \& Turek, 1985). Much of our understanding of the neuroendocrine events involved in the photoperiodic control of reproduction is derived from studies on three mammalian species: the golden hamster and the Djungarian hamster (both longday breeders) and the sheep (a short-day breeder). In sheep, long photoperiods (more than $13 \mathrm{~h}$ light per day) induce reproductive quiescence, whereas short photoperiods (less than $12 \mathrm{~h}$ light per day) stimulate gonadal reactivation and reproduction; in hamsters the effect is just the opposite. However, the photoperiod induced changes are not permanent. In hamsters, for examples, the short-day induced gonadal quiescence persists only for about 18 weeks. After 18 weeks gonadal reactivation may occur even if the animal remains exposed to short days (Turek et al., 1975). Before gonadal quiescence can be induced by short photoperiods again, the hamsters would have to be kept under long day conditions for several weeks (Stetson et al., 1977).

Photoperiodic animals can measure the length of day very precisely. In early work on the mechanisms of photoperiodic time measurement it was assumed that animals determine the total duration of light and darkness by some sort of 'hourglass' mechanism or interval timer (Farner et al., 1953). Since then several experiments using unusual light-dark cycles ('resonance', ' $T$ ' and 'night interrupt' experiments) have revealed, that animals measure the length of day by comparing the external light-dark cycle against an endogenous circadian rhythm of light sensitivity (reviewed in Keefe \& Turek, 1985). In those experiments light was presented only for short periods under otherwise constant darkness. The animal interpreted as either long or short days only those light pulses that were applied during a certain phase of the circadian photosensitivity rhythm.

An important part of the photoperiodic time measurement seems to be the circadian system in the SCN. Bilateral lesions of the SCN abolish photoperiod induced changes in the reproductive status; lesioned animals retain their gonadal 
function regardless of the light-dark cycle (hamsters: Rusak \& Morin, 1976; Stetson \& Watson-Whitmyre, 1976; ewes: Domanski et al., 1980). The neural information about day length is transferred to the endocrine hypothalamicpituitary-gonadal axis via the pineal organ (Reiter, 1980a,b). Using anatomical and physiological techniques the following pathway between the $\mathrm{SCN}$ and the pineal organ has been discovered (reviewed in Keefe \& Turek, 1985). SCN efferents project to regions of the paraventricular nuclei of the hypothalamus (Klein et al., 1983; Pickard \& Turek, 1983; Lehman et al., 1984; Inouye \& Turek, 1986). The paraventricular nuclei project to the intermediolateral nuclei of the spinal cord (Swanson \& Kuypers, 1980) which innervate the superior cervical ganglia (Rando et al., 1981). A beta-adrenergic input from the superior cervical ganglia controls the activity of pineal $\mathrm{N}$-acetyltransferase, thereby regulating the melatonin synthesis in the pineal organ (Zatz, 1981; Klein, 1985). In a number of photoperiodic species, pinealectomy prevents the short-day induced gonadal regression (reviewed in Hoffman, 1981).

The SCN regulates the rhythmic timing of production of melatonin so that melatonin levels are high at night and low during the day (Goldman, 1983; Goldman \& Darrow, 1983). Recent studies on both Djungarian hamsters and sheep suggest that the duration of high night-time levels in circulating melatonin determines whether the photoperiod will be interpreted as a long or a short day (Carter \& Goldman, 1983a,b; Bittman \& Karsch, 1984). It is not known yet how melatonin alters hypothalamic-pituitary functions and how the signal of melatonin duration is transformed into a change in neuroendocrine gonadal activity.

\section{Conclusion}

Biological rhythms have been observed in practically all groups of laboratory animals and at every level of physiological and behavioural organization even under standardized laboratory conditions. Biological rhythms are important for the health and wellbeing of the organism for two reasons. First, they allow an optimal timing of biological activities within the context of physical environmental cycles. Circadian and circannual rhythms serve as biological clocks that enable the organism to anticipate periodic events in its environment so that it can initiate slow processes on time. Second, biological rhythms provide an internal framework for the temporal organization of physiology and behaviour thus contributing to the maintenance of a balanced internal milieu.

Biological rhythms are classified according to their period as circadian, ultradian, infradian, and seasonal or circannual rhythms. In recent years, researchers have discovered some of the underlying pacemaker systems and physiological mechanisms involved in the generation, entrainment and coupling of biological rhythms. Circadian rhythms are generated by a multioscillator system located in the SCN and are synchronized to the external $24 \mathrm{~h}$ light-dark cycle. Ultradian rhythms can be generated by a variety of different neural pacemaker systems and are characterized by the diversity of their rhythmic phenomena. Many infradian rhythms are the result of changes in gonadal hormone levels during the oestrous cycle and can only be observed in female animals. Many annual rhythms are correlated with changes in the reproductive functions over the year. Photoperiodic changes of reproductive functions are controlled through complex interactions between the SCN, the pineal, and the hypothalamicpituitary-gonadal axis. Frequency and amplitude of ultradian rhythms are often modulated on a circadian time scale. The circadian system must be considered the most important biological clock since it affects the regulation of all other biological rhythms. Many key events within the oestrous cycle are timed by the circadian system, and the photoperiodic control of seasonal rhythms involves the circadian clock for measuring day length.

Most, if not all, physiological systems are affected by biological rhythms, and laboratory animal science should take this into account in designing experimental schedules. For example, 
contradictory results from different laboratories might be due simply to differences in the daily schedules in which experiments are being performed. Different findings on the periodicity of ultradian rhythms, such as episodic hormonal fluctuations, might be due to different sampling intervals. Such pitfalls can be avoided by scanning the unknown rhythmicity of the investigated variable with repeated experiments performed at several time points in the cycle of a rhythm in order to determine characteristic phase points, such as the daily peak or low of a circadian rhythm. These should serve as reference points when selecting the times to perform the real experiments. If this chronobiological approach cannot be taken because of methodological or other constraints, experimenters should at least provide information about their experimental time schedule and the light-dark cycle of their animals in order to allow others to reproduce or compare their results.

\section{Acknowledgments}

I am grateful to Professors Fred W Turek and Joe S Takahashi for their continuing encouragement and helpful advice. My thanks also go to Andreas Herrmann, Amy Jetton, Janet E Joy, Jill J Milette, Rick S Smith, and Beth E F Wee for their suggestions and comments on an earlier draft of this manuscript. Preparation of this article was supported by Deutsche Forschungsgemeinschaft (II 02-WO 354/2-1).

\section{References}

Aguilar-Roblero R, Garía-Hernández F, Aguilar R, Arankowsky-Sandoval G \& Drucker-Colin R (1986) Suprachiasmatic nucleus transplants function as an endogenous oscillator only in constant darkness. Neuroscience Letters 69, 47-52

Ajika K \& Ochi J (1978) Serotonergic projections to the suprachiasmatic nucleus and the median eminence of the rat: identification by fluorescence and electron microscope. Journal of Anatomy 127, 563-576

Albers HE, Gerall AA \& Axelson JF (1981a) Circadian rhythm dissociation in the rat: effects of long-term constant illumination. Neuroscience Letters 25, 89-94

Albers HE, Gerall AA \& Axelson JF (1981b) Effect of reproductive state on circadian periodicity in the rat. Physiology \& Behavior 26, 21-25

Alleva JJ, Waleski MV, Alleva FR \& Umberger EJ (1968) Synchronizing effect of photoperiodicity on ovulation in hamsters. Endocrinology 82, 1227-1235

Aschoff J (1962) Spontane lokomotorische Aktivität. In Handbuch der Zoologie (eds JG Helmcke, H von Lengerken \& D Starck), vol. 8, pp. 1-76. Berlin: Walter de Gruyter

Aschoff J (1979a) Circadian rhythms: influences of internal and external factors on the period measured in constant conditions. Zeitschrift für Tierpsychologie 49, 225-249

Aschoff J (1979b) Circadian rhythms: general features and endocrinological aspects. In Endocrine Rhythms (ed D Krieger), pp.1-61, New York: Raven Press

Aschoff J \& Gerkema MP (1985) On diversity and uniformity of ultradian rhythms. In Ultradian Rhythms in Behavior and Physiology (eds H Schulz \& P Lavie), pp. 321-334. Berlin: Springer Verlag

Aschoff J, von Goetz C \& Honma KI (1983) Restricted feeding in rats: effect of varying feeding cycles. Zeitschrift für Tierpsychologie 63, 91-111

Aschoff J \& Pohl H (1978) Phase relations between a circadian rhythm and its zeitgebers within the range of entrainment. Naturwissenschaften 65, 80-84
Aschoff J \& Tokura H (1986) Circadian activity rhythms in squirrel monkeys: entrainment by temperature cycles. Journal of Biological Rhythms 1, 91-99

Berk ML \& Finkelstein JA (1981) An autoradiographic determination of the efferent projections of the suprachiasmatic nucleus of the hypothalamus. Brain Research 226, 1-13

Bittman EL \& Karsch FJ (1984) Nightly duration of pineal melatonin secretion determines the reproductive response to inhibitory day length in the ewe. Biology of Reproduction 30, $558-593$

Boulos Z, Rosenwasser A \& Terman M (1980) Feeding schedules and the circadian organization of behavior in the rat. Behavioral Brain Research 1, 39-65

Boulos Z \& Terman M (1979) Splitting of circadian rhythms in the rat. Journal of Comparative Physiology A 134, 75-83

Boulos Z \& Terman M (1980) Food availability and daily biological rhythms. Neuroscience \& Biobehavioral Reviews 4, 119-131

Broughton RJ (1985) Three central issues concerning ultradian rhythms. In Ultradian Rhythms in Behavior and Physiology (eds H Schulz \& P Lavie), pp. 217-233. Berlin: Springer Verlag

Büttner D \& Wollnik F (1984) Strain-differentiated circadian and ultradian rhythms in locomotor activity of the laboratory rat. Behavior Genetics 14, 137-152

Campbell CS \& Turek FW (1981) Cyclic function of the mammalian ovary. In Handbook of Behavioral Neurobiology, Vol. 4: Biological Rhythms (ed. J Aschoff), pp. 523-545. New York: Plenum Press

Card JP \& Moore RY (1982) Ventral lateral geniculate nucleus efferents to the rat suprachiasmatic nucleus exhibit avian pancreatic polypeptide-like immunoreactivity. Journal of Comparative Neurology 206, 390-396

Carter DS \& Goldman BD (1983a) Antigonadal effects of timed melatonin infusion in pinealectomized male Djungarian hamsters (Phodopus sungorus sungorus): Duration is the critical parameter. Endocrinology 113, 1261-1267 
Carter DS \& Goldman BD (1983b) Progonadal role of the pineal in the Djungarian hamster (Phodopus sungorus sungorus): Mediation by melatonin. Endocrinology 113, $1268-1273$

Cheung PW \& McCormack CE (1983) Splitting of the locomotor activity rhythm in rats by exposure to continuous light. American Journal of Physiology 244, R573-R576

Connolly MS \& Lynch CB (1981) Circadian variation of strain differences in body temperature and activity in mice. Physiology \& Behavior 27, 1045-1049

Connolly MS \& Lynch CB (1983) Classical genetic analysis of circadian body temperature rhythms in mice. Behavior Genetics 13, 491-500

Daan S \& Aschoff J (1981) Short-term rhythms in activity. In Handbook of Behavioral Neurobiology, Vol. 4: Biological Rhythms (ed. J. Aschoff), pp. 491-522. New York: Plenum Press

Daan S, Damassa D, Pittendrigh CS \& Smith ER (1975) An effect of castration and testosterone replacement on a circadian pacemaker in mice (Mus musculus). Proceedings of the National Academy of Sciences, USA 72, 3744-3747

Daan S \& Pittendrigh CS (1976) A functional analysis of circadian pacemakers in nocturnal rodents. II. The variability of phase response curves. Journal of Comparative Physiology A 106, 253-266

Daan S \& Slopsema S (1978) Short-term rhythms in foraging behavior of the common vole, Microtus arvalis. Journal of Comparative Physiology A 127, 215-227

Domanski E, Przekop F \& Polkowska J (1980) Hypothalamic centres involved in the control of gonadotropin secretion. Journal of Reproduction and Fertility 58, 493-499

Earnest DJ \& Sladek CD (1987) Circadian vasopressin release from perfused rat suprachiasmatic explants in vitro: effects of acute stimulation. Brain Research 422, 398-402

Earnest DJ \& Turek FW (1982) Splitting of the circadian rhythm of activity in hamsters: Effects of exposure to constant darkness and subsequent re-exposure to constant light. Journal of Comparative Physiology A 145, 405-411

Earnest DJ \& Turek FW (1983) Role for acetylcholine in mediating effects of light on reproduction. Science 219, 77-79

Ebihara S, Tsuji K \& Kondo K (1978) Strain differences of the mouse's free-running circadian rhythm in continuous darkness. Physiology Behavior 20, 795-799

Enright JT (1981) Methodology. In Handbook of Behavioral Neurobiology, Vol. 4: Biological Rhythms (ed. J. Aschoff), pp. 11-19. New York: Plenum Press

Eikelboom R \& Tannenbaum GS (1983) Effects of obesity inducing ventromedial hypothalamic lesions on pulsatile growth hormone and insulin secretion: evidence for the existence of a growth hormone releasing factor. Endocrinology 112, 212-219

Farner DS, Mewaldt LR \& Irving SD (1953) The roles of darkness and light in the activation of avian gonads. Science 118, 351-352

Finkelstein JS, Baum FR \& Campbell CS (1978) Entrainment of the female hamster to reversed photoperiod: Role of the pineal. Physiology \& Behavior 21, 105-111

Fitzgerald KM \& Zucker I (1976) Circadian organization of the estrous cycle of the golden hamster. Proceedings of the National Academy of Sciences, USA 73, 2923-2927

Flood DG \& Gibbs FP (1982) Species differences in [14C]2-deoxyglucose uptake by suprachiasmatic nuclei. Brain Research 232, 200-205
Foote WE, Tabor-Pierce E \& Edwards L (1978) Evidence for a retinal projection to the midbrain raphe of the cat. Brain Research 156, 135-140

Fuller CA, Sulzman FM \& Moore-Ede MC (1979) Circadian control of thermoregulation in the squirrel monkey, Saimiri sciureus. American Journal of Physiology 236, R153-R161

Gallo RV (1981) Pulsatile release during the ovulatory LH surge on proestrus in the rat. Biology of Reproduction 24, 100-104

García-Hernández F, Aguilar-Roblero R \& Drucker-Colín R (1987) Transplantation of the fetal occipital cortex to the third ventricle of $\mathrm{SCN}$-lesioned rats induces a diurnal rhythm in drinking behavior. Brain Research 418, 193-197

Gerkema MP \& Daan S (1985) Ultradian rhythms in behavior: The case of the common vole (Microtus arvalis). In Ultradian Rhythms in Physiology and Behavior (eds $\mathrm{H}$ Schulz \& P Lavie), pp. 11-31. Berlin: Springer Verlag

Gibbs FP (1979) Fixed interval feeding does not entrain the circadian pacemaker in blind rats. American Journal of Physiology 236, R249-R253

Goldman BD (1983) The physiology of melatonin in mammals. In Pineal Research Reviews (ed RJ Reiter), vol. 1, pp. 145-182. New York: Alan R. Liss

Goldman BD \& Darrow JM (1983) The pineal gland and mammalian photoperiodism. Neuroendocrinology 37 , 386-396

Green DJ \& Gillette R (1982) Circadian rhythm of firing rate recorded from single cells in the rat suprachiasmatic brain slice. Brain Research 245, 198-200

Groos GA (1982) The neurophysiology of the mammalian suprachiasmatic nucleus and its visual afferents. In Vertebrate Circadian Rhythms: Structure and Physiology (eds J Aschoff, S Daan \& GA Groos), pp. 96-105. Berlin: Springer Verlag

Guttman R, Lieblich I \& Gross R (1975) Behavioral correlates of estrous cycle stages in laboratory mice. Behavioral Biology 13, 127-132

Gwinner E (1981) Circannual systerns. In Handbook of Behavioral Neurobiology, Vol. 4: Biological Rhythms (ed J Aschoff), pp. 391-410. New York: Plenum Press

Halberg F (1959) Physiological 24-hour periodicity: general and procedural considerations with reference to the adrenal cycle. Zeitschrift für Vitamin-. Hormon- und Fermentforschung 10, 225-296

Halberg F, Engeli M, Hamburger C \& Hillman VD (1965) Spectral resolution of low-frequency, small-amplitude rhythms in excreted 17-ketosteroids: probably androgeninduced circaseptan desynchronization. Acta Endocrinologica $103,1-54$

Harrington ME, Nance DM \& Rusak B (1987) Doublelabeling of neuropeptide $\mathrm{Y}$-immunoreactive neurons which project from the geniculate to the suprachiasmatic nuclei. Brain Research 410, 275-282

Hegmann JP \& Possidente B ( 1981) Estimating genetic correlations from inbred strains. Behavior Genetics 11, 103-114

Hendrickson AE, Wagoner N \& Cowan WM (1972) An autoradiographic and electron microscopic study of the retino-hypothalamic connections. Zeitschrift für Zellforschung 135, 1-26

Hoffmann K (1971) Splitting of the circadian rhythm as a function of light intensity. In Biochronometry (ed. M Menaker), pp. 134-150. Washington DC: National Academy of Sciences 
Hoffmann K (1981) Photoperiodism in vertebrates. In Handbook of Behavioral Neurobiology, Vol. 4: Biological Rhythms (ed. J. Aschoff), pp. 449-473. New York: Plenum Press

Honma KI \& Honma S (1985a) Ultradian rhythms in locomotor activity, deep body temperature and plasma corticosterone levels in rats: two different origins? In Ultradian Rhythms in Behavior and Physiology (eds $\mathrm{H}$ Schulz \& P Lavie), pp. 77-94. Berlin: Springer Verlag

Honma S \& Honma KI (1985b) Interaction between circadian and ultradian rhythms of spontaneous locomotor activity in rats during the early developmental period. In Ultradian Rhythms in Behavior and Physiology (eds H Schulz \& P. Lavie), pp. 95-109. Berlin: Springer Verlag

Honma KI, Honma S \& Hiroshige T (1987) Activity rhythms in the circadian domain appear in suprachiasmatic nuclei lesioned rats given metamphetamine. Physiology \& Behavior 40, 767-774

Hotz MM \& Turek FW (1987) Inbred strain analysis of circadian rhythms in the golden hamster. Behavior Genetics 17, 626

Inouye ST (1982) Ventromedial hypothalamic lesions eliminate anticipatory activities of restricted daily feeding schedule in the rat. Brain Research 250, 183-187

Inouye ST (1984) Light responsiveness of the suprachiasmatic nucleus within the island with the retino-hypothalamic tract spared. Brain Research 294, 263-268

Inouye ST \& Kawamura H (1979) Persistence of circadian rhythmicity in a mammalian hypothalamic 'island' containing the suprachiasmatic nucleus. Proceedings of the National Academy of Sciences, USA 76, 5962-5966

Inouye ST \& Kawamura H (1982) Characteristics of a circadian pacemaker in the suprachiasmatic nucleus. Journal of Comparative Physiology A 146, 153-160

Inouye ST \& Turek FW (1986) Horizontal knife cuts either ventral or dorsal of the hypothalamic paraventricular nucleus block testicular regression in golden hamsters maintained in short days. Brain Research 370, 102-107

Kawamura H \& Nihonmatsu I (1985) The suprachiasmatic nucleus as a circadian rhythm generator. In Circadian Clocks and Zeitgebers (eds T Hiroshige \& KI Honma), pp. 55-63. Sapporo: Hokkaido University Press

Keefe DL, Earnest DJ, Nelson D, Takahashi JS \& Turek FW (1987) A cholinergic antagonist, mecamylamine, blocks the phase-shifting effects of light on the circadian rhythm of locomotor activity in the golden hamster. Brain Research 403, 308-312

Keefe DL \& Turek FW (1985) Circadian time keeping processes in mammalian reproduction. Oxford Reviews of Reproductive Biology 7, 346-400

Klein DC (1985) Photoneural regulation of the mammalian pineal gland. In Photoperiodism, Melatonin and the Pineal (Ciba Foundation Symposium 117), pp. 38-56. London: Pitman

Klein DC, Smoot R, Weller JL, Higa S, Markey SP, Creed J \& Jacobowitz DM (1983) Lesions of the paraventricular nucleus area of the hypothalamus disrupt the suprachiasmatic-spinal cord circuit in the melatonin rhythm generating system. Brain Research Bulletin 10, 647-652

Kleitman N (1961) The nature of dreaming. In The Nature of Sleep (eds GEW Wolstenholme \& M O'Connor), pp. 349-364. London: Churchill

Kleitman N (1982) Basic rest-activity cycle -22 years later. Sleep 5, 311-317
Knobil E \& Hotchkiss J (1985) The circhoral gonadotropin releasing hormone $(\mathrm{GnRH})$ pulse generator of the hypothalamus and its physiological significance. In Ultradian Rhythms in Physiology and Behavior (eds $\mathrm{H}$ Schulz \& P Lavie), pp. 32-40. Berlin: Springer Verlag

Krieger DT (1980) Ventromedial hypothalamic lesions abolish food-shifted circadian adrenal and temperature rhythmicity. Endocrinology 106, 649-654

Krieger DT, Hauser H \& Krey LC (1977) Suprachiasmatic nuclear lesions do not abolish food-shifted circadian adrenal and temperature rhythmicity. Science 197, 398-399

Lehman MN, Bittman EK \& Newman SW (1984) Role of the hypothalamic paraventricular nucleus in neuroendocrine responses to daylength in the golden hamster. Brain Research 308, 25-32

Lehman MN, Silver R, Gladstone WR, Kahn RM, Gibson M \& Bittman EL (1987) Circadian rhythmicity restored by neural transplant. Immunocytochemical characterization of the graft and its integration with the host brain. Journal of Neuroscience 7, 1626-1638

Levine JE \& Ramirez VD (1982) Luteinizing hormone-release during the rat estrous cycle and after ovariectomy, as estimated with push-pull cannulae. Endocrinology 111, 1439-1448

Lydic R, Albers HE, Tepper B \& Moore-Ede MC (1982) Three-dimensional structure of the mammalian suprachiasmatic nuclei: a comparative study of five species. Journal of Comparative Neurology 204, 225-237

Mahesh VB (1985) The dynamic interaction between steroids and gonadotropins in the mammalian ovulatory cycle. Neuroscience \& Biobehavioral Reviews 9, 245-260

Moore RY (1978) Central neural control of circadian rhythms. In Frontiers in Neuroendocrinology (eds WF Ganong \& L Martini), vol 5, p. 185-206. New York: Raven Press

Moore RY (1983) Organization and function of a central nervous system circadian oscillator: the suprachiasmatic hypothalamic nucleus. Federation Proceedings 42, 2783-2789

Moore RY \& Card JP (1985) Visual pathways and the entrainment of circadian rhythms. Annals of the New York Academy of Sciences 453, 123-133

Moore RY \& Eichler VB (1972) Loss of a circadian adrenal corticosterone rhythm following suprachiasmatic nucleus lesions in the rat. Brain Research 42, 201-206

Moore RY \& Klein DC (1974) Visual pathways and the central neural control of a circadian rhythm in pineal serotonin $\mathrm{N}$-acetyltransferase activity. Brain Research 71, 17-33

Moore RY \& Lenn NJ (1972) A retinohypothalamic projection in the rat. Journal of Comparative Neurology 146, $1-14$

Morin LP (1980) Effect of ovarian hormones on synchrony of hamster circadian rhythms. Physiology \& Behavior 24, 741-749

Morin LP \& Cummings LA (1982) Splitting of wheelrunning rhythms by castrated or steroid treated male and female hamsters. Physiology \& Behavior 29, 665-675

Morin LP, Fitzgerald KM \& Zucker I (1977) Estradiol shortens the period of hamster circadian rhythms. Science 196, 305-307

Mosko S \& Moore RY (1978) Neonatal suprachiasmatic nucleus ablation: Absence of functional and morphological plasticity. Proceedings of the National Academy of Sciences, USA 75, 6243-6246 
Mrosovsky N, Melnyk RB, Lang K, Hallonquist JD, Boshes M \& Joy JE (1980) Infradian rhythms in dormice (Glis glis). Journal of Comparative Physiology A 137, 315-339

Murakami N, Takahashi K \& Kawashima K (1984) Effect of light on the acetylcholine concentrations of the suprachiasmatic nucleus in the rat. Brain Research 311, 358-360

Pengelley ET \& Asmundson SJ (1974) Circannual rhythmicity in hibernating mammals. In Circannual Clocks (ed. ET Pengelley), pp. 95-160. New York: Academic Press

Peterson GM, Watkins WB \& Moore RY (1980) The suprachiasmatic hypothalamic nuclei of the rat. VI. Vasopressin neurons and circadian rhythmicity. Behavioral and Neural Biology 29, 236-245

Pickard GE (1982) The afferent connections of the suprachiasmatic nucleus of the golden hamster with emphasis on the retinohypothalamic projection. Journal of Comparative Neurology 211, 65-83

Pickard GE, Ralph MR \& Menaker M (1987) The intergeniculate leaflet partially mediates effects of light on circadian rhythms. Journal of Biological Rhythms 2, 35-56

Pickard GT \& Turek FW (1983) The hypothalamic paraventricular nucleus (PVN) mediates the photoperiodic control of reproduction but not the effects of light on the circadian rhythm of activity. Neuroscience Letters 43, $67-72$

Pittendrigh CS (1960) Circadian rhythms and the circadian organization of living systems. Cold Spring Harbor Symposium of Quantitative Biology 25, 159-184

Pittendrigh CS (1974) Circadian oscillations in cells and the circadian organization of multicellular systems. In The Neuroscience Third Study Program (eds FO Schmitt \& FG Worden), pp. 437-458. Cambridge: MIT Press

Pittendrigh CS (1981) Circadian systems: Entrainment. In Handbook of Behavioral Neurobiology, Vol. 4: Biological Rhythms (ed J Aschoff), pp. 95-124. New York: Plenum Press

Pittendrigh CS \& Calderola PC (1973) General homeostasis of the frequency of circadian oscillations. Proceedings of the National Academy of Sciences, USA 70, 2697-2701

Pittendrigh CS \& Daan S (1976a) A functional analysis of circadian pacemakers in nocturnal rodents. 1 . The stability and lability of spontaneous frequency. Journal of Comparative Physiology A 106, 223-252

Pittendrigh CS \& Daan S (1976b) A functional analysis of circadian pacemakers in nocturnal rodents. V. Pacemaker structure: A clock for all seasons. Journal of Comparative Physiology A 106, 333-355

Possidente B \& Hegmann JP (1980) Circadian complexes: circadian rhythms under common gene control. Journal of Comparative Physiology B 139, 121-125

Possidente B, Hegmann JP, Carlson L \& Elder B (1982) Pigment mutations associated with altered circadian rhythms in mice. Physiology \& Behavior 28, 389-392

Ralph MR \& Menaker M (1987) A genetic mutation of the circadian system in golden hamsters. Neuroscience Abstracts 13, 65.10, 213

Rando TA Bowers CW \& Zigmond RE (1981) Localization of neurons in the rat spinal cord which project to the superior cervical ganglion. Journal of Comparative Neurology 196, 73-83

Reiter RJ (1980a) The pineal and its hormones in the control of reproduction in mammals. Endocrine Reviews 1, 109-131
Reiter RJ (1980b) The pineal gland: a regulator of regulators. Progress in Psychobiology and Physiological Psychology 9, 232-255

Reppert SM \& Schwartz WJ (1983) Maternal coordination of the fetal biological clock in utero. Science 220,969-971

Reppert SM \& Schwartz WJ (1984) The suprachiasmatic nuclei of the fetal rat: characterization of a functional circadian clock using $14 \mathrm{C}$-labeled deoxyglucose. Journal of Neuroscience 4, 1677-1682

Richter CP (1967) Sleep and activity: Their relation to the 24-hour clock. In Sleep and Altered States of Consciousness, Vol. XLV, Association for Research in Nervous and Mental Disease, pp. 8-29. Baltimore: The Williams \& Wilkins Company

Rosenwasser AM \& Adler NT (1986) Structure and function in circadian timing systems: evidence for multiple coupled circadian oscillators. Neuroscience \& Behavioral Reviews 10, 431-448

Rusak B (1977) The role of the suprachiasmatic nuclei in the generation of circadian rhythms in the golden hamster, Mesocricetus auratus. Journal of Comparative Physiology A 118, 145-164

Rusak B (1979) Neural mechanisms for entrainment and generation of mammalian circadian rhythms. Federation Proceedings 38, 2589-2595

Rusak B (1982) Physiological models of the rodent circadian system. In Vertebrate Circadian Systems: Structure and Physiology Eds J Aschoff, S Daan \& GA Groos), pp. 62-74. Berlin: Springer Verlag

Rusak B \& Groos GA (1982) Suprachiasmatic stimulation phase shifts rodent circadian rhythms. Science 215 , $1407-1409$

Rusak B \& Morin LP (1976) Testicular response to photoperiod are blocked by lesions of the $\mathrm{SCN}$ in golden hamsters. Biology of Reproduction 15, 366-374

Rusak B \& Zucker I (1979) Neural regulation of circadian rhythms. Physiological Reviews 59, 449-526

Scheuch GC, Johnson W, Conner RL \& Silver J (1982) Investigation of circadian rhythms in a genetically anophthalmic mouse strain: correlation of activity patterns with suprachiasmatic nuclei hypogenesis. Journal of Comparative Physiology 149, 333-338

Schulz H \& Lavie P (1985) Ultradian Rhythms in Physiology and Behavior. Berlin: Springer Verlag

Schwartz WJ, Reppert SM, Eagan SM \& Moore-Ede MC (1983) In vivo metabolic activity of the suprachiasmatic nuclei: a comparative study. Brain Research 274, 184-187

Shibata S, Liou SY, Ueki S \& Oomura Y (1984) Influence of environmental light-dark cycle and enucleation on activity of suprachiasmatic neurons in slice preparation. Brain Research 302, 75-81

Sofroniew MV \& Weindl A (1982) Neuroanatomical organization and connections of the suprachiasmatic nucleus. In Vertebrate Circadian Systems: Structure and Physiology (eds J Aschoff, S Daan \& GA Groos), pp. 75-86. Berlin: Springer Verlag

Soper BD \& Weick RF (1980) Hypothalamic and extrahypothalamic mediation of pulsatile discharges of luteinizing hormone in the ovariectomized rat. Endocrinology 106, 348-355

Sridaran R \& McCormack CE (1977) Predicting the time of ovulation in rats by monitoring running activity. Federation Proceedings 36, Abstr. 226, 313 
Stephan FK (1982) Limits of entrainment to periodic feeding in rats with suprachiasmatic lesions. In Vertebrate Circadian Systems: Structure and Physiology (eds J Aschoff, S Daan \& GA Groos), pp. 120-128. Berlin: Springer Verlag

Stephan FK (1983) Circadian rhythms in the rat: constant darkness, entrainment to $\mathrm{T}$ cycles and skeleton photoperiods. Physiology \& Behavior 30, 451-462

Stephan FK (1984) Phase shifts of circadian rhythms in activity entrained to food access. Physiology \& Behavior 32, 663-671

Stephan FK, Berkley KJ \& Moss RL (1981) Efferent connections of the rat suprachiasmatic nucleus. Neuroscience 6, 2625-2641

Stephan FK, Swann JM \& Sisk CL (1979a) Anticipation of 24-hr feeding schedules in rats with lesions of the suprachiasmatic nucleus. Behavioral and Neural Biology $25,346-363$

Stephan FK, Swann JM \& Sisk CL (1979b) Entrainment of circadian rhythms by feeding schedules in rats with suprachiasmatic lesions. Behavioral and Neural Biology 25, 545-554

Stephan FK \& Zucker I (1972a) Circadian rhythms in drinking behavior and locomotor activity of rats are eliminated by hypothalamic lesions. Proceedings of the National Academy of Sciences, USA 69, 1583-1586

Stephan FK \& Zucker I (1972b) Rat drinking rhythms: central visual pathways and endocrine factors mediating responsiveness to environmental illumination. Physiology \& Behavior 8, 315-326

Stetson MH \& Gibson JT (1977) The estrous cycle in golden hamsters: a circadian pacemaker times preovulatory gonadotropin release. Journal of Experimental Zoology 201, 289-294

Stetson MH \& Watson-Whitmyre M (1976) Nucleus suprachiasmaticus: the biological clock in the hamster? Science 191, 197-199

Stetson MH, Watson-Whitmyre M \& Matt KS (1977) Termination of photorefractoriness in golden hamster photoperiodic requirements. Journal of Experimental Zoology 202, 81-88

Swann JM \& Turek FW (1985) Multiple circadian oscillators regulate the timing of behavioral and endocrine rhythms in female golden hamsters. Science 228, 898-900

Swanson LW \& Cowan WM (1975) The efferent connections of the suprachiasmatic nucleus of the hypothalamus. Journal of Comparative Neurology 160, 1-12

Swanson LW, Cowan WM \& Jones EG (1974) An autoradiographic study of the efferent connections of the ventral lateral geniculate nucleus in the albino rat and the cat. Journal of Comparative Neurology 156, 143-164

Swanson LW \& Kuypers HGJM (1980) The paraventricular nucleus of the hypothalamus: cytoarchitectonic subdivisions and organization of projections to the pituitary, dorsal vagal complex, and spinal cord as demonstrated by retrograde fluorescence double-labelling methods. Journal of Comparative Neurology 194, 555-570

Takahashi JS \& Menaker M (1980) Interaction of estradiol and progesterone: effects on circadian locomotor rhythm of female golden hamsters. American Journal of Physiology 239, R497-R504

Takahashi JS \& Zatz M (1982) Regulation of circadian rhythmicity. Science 217, 1104-1111
Tokura H \& Aschoff J (1983) Effects of temperature on the circadian rhythm of pig-tailed macaque Macaca nemestrina. American Journal of Physiology 14, R800-R804

Turek FW (1985) Circadian neural rhythms in mammals. Annual Review of Physiology 47, 49-64

Turek FW (1987) Pharmacological probes of the mammalian circadian clock: use of the phase response curve approach. Trends in Pharmacological Sciences 8, 2121-217

Turek FW, Earnest DJ \& Swann J (1982) Splitting of the circadian rhythm of activity in hamster. In Vertebrate Circadian Systems: Structure and Physiology (eds J Aschoff, S Daan \& GA Groos), pp. 203-213. Berlin: Springer Verlag

Turek FW, Elliot JA, Alvis JD \& Menaker M (1975) Effect of prolonged exposure to nonstimulatory photoperiods on the activity of the neuroendocrine-testicular axis of golden hamsters. Biology of Reproduction 13, 475-481

Turek FW, Jacobson CD \& Gorski RA (1980) Lesions of the suprachiasmatic nucleus affect photoperiod-induced changes in the sensitivity of the hypothalamic-pituitary axis to testosterone feedback. Endocrinology 107, 942-947

Turek FW \& Van Cauter E (1988) Rhythms in reproduction. In Physiology of Reproduction (eds E Knobil \& J Neill). New York: Raven Press (in press)

Van Cauter E (1981) Quantitative methods for the analysis of circadian and episodic hormone fluctuations. In Circadian and Episodic Variations (eds E Van Cauter \& G Copinschi), pp. 1-25. Nyhoff: The Hague

Van Cauter E \& Honinckx (1985) Pulsatility of pituitary hormones. In Ultradian Rhythms in Physiology and Behavior (eds H Schulz \& P Lavie), pp. 41-60. Berlin: Springer Verlag

Van den Pol AN (1980) The hypothalamic suprachiasmatic nucleus of rat: intrinsic anatomy. Journal of Comparative Neurology 191, 661-702

Van den Pol AN \& Tsujimoto KL (1985) Neurotransmitters of the hypothalamic suprachiasmatic nucleus: Immunocytochemical analysis of 25 neuronal antigens. Neuroscience 15, 1049-1086

Vollrath L (1982) Circadian and infradian activity rhythms in the mammalian pineal body. In Vertebrate Circadian Systems: Structure and Physiology (eds J Aschoff, S Daan \& GA Groos), pp. 141-146. Berlin: Springer Verlag

Wever RA (1982) Behavioral aspects of circadian rhythms. In Rhythmic Aspects of Behavior (eds FM Brown \& RC Graeber), pp. 105-171, Hillsdale: Lawrence Erlbaum

Wirz-Justice A, Groos GA \& Wehr TA (1982) The neuropharmacology of circadian timekeeping in mammals. In Vertebrate Circadian Systems: Structure and Physiology (eds J Aschoff, S Daan \& GA Groos), pp. 183-193. Berlin: Springer Verlag

Wollnik F \& Döhler K-D (1986) Effects of adult or perinatal hormonal environment on ultradian rhythms in locomotor activity of laboratory LEW/Ztm rats. Physiology \& Behavior 38, 229-240

Wollnik F, Gärtner K \& Büttner D (1987) Genetic analysis of circadian and ultradian locomotor activity rhythms in laboratory rats. Behavior Genetics 17, 167-178

Wollnik F \& Turek FW (1987) Effects of complete and partial $\mathrm{SCN}$ lesions on ultradian and circadian locomotor activity rhythms in LEW/Ztm rats. Neuroscience Abstracts 13, $127.12,607$ 
Zatz M (1979) A neuropharmacological approach to the circadian oscillator regulating rat pineal serotonin $\mathrm{N}$ acetyltransferase activity. In Biological Rhythms and Their Central Mechanism (eds M Suda, O Hayaishi \& K Nakagawa), pp. 149-158. Amsterdam: Elsevier

Zatz M (1981) Pharmacology of the rat pineal gland. In The Pineal Gland vol. I: Anatomy and Biochemistry (ed. RJ Reiter), pp. 229-242, Boca Raton: CRC Press

Zatz M \& Brownstein MJ (1979) Intraventricular carbachol mimics the effect of light on the circadian rhythm in the rat pineal gland. Science 203, 358-360

Zatz M \& Brownstein MJ (1981) Injection of alpha-bungarotoxin near the suprachiasmatic nucleus blocks the effects of light on nocturnal pineal enzyme activity. Brain Research 213, 438-442

Zatz M \& Herkenham M (1981) Intraventricular carbachol mimics the phase-shifting effect of light on the circadian rhythm of wheel-running activity. Brain Research 212, 234-238 